\title{
a-Acetoxyarone synthesis via iodine-catalyzed and tert-butyl hydroperoxide-mediateded self-intermolecular oxidative coupling of aryl ketones
}

\author{
Liquan Tan*, Cui Chen and Weibing Liu
}

\author{
Letter \\ Address: \\ College of Chemical Engineering, Guangdong University of \\ Petrochemical Technology, 2 Guandu Road, Maoming 525000, P. R. \\ China. Fax: +86-668-2923575; Tel: +86-668-2923444 \\ Email: \\ Liquan Tan* - touching522@gdupt.edu.cn \\ * Corresponding author \\ Keywords: \\ aryl ketones; iodine; self-intermolecular oxidative coupling \\ self-sequential assembly; TBHP
}

Beilstein J. Org. Chem. 2017, 13, 1079-1084.

doi:10.3762/bjoc. 13.107

Received: 12 April 2017

Accepted: 16 May 2017

Published: 06 June 2017

Associate Editor: D. Y.-K. Chen

(c) 2017 Tan et al.; licensee Beilstein-Institut.

License and terms: see end of document.

\begin{abstract}
We present a metal-free method for $\alpha$-acetoxyarone synthesis by self-intermolecular oxidative coupling of aryl ketones using $\mathrm{I}_{2}$-tert-butyl hydroperoxide (TBHP). Under the optimum conditions, various aryl ketones gave the corresponding products in moderate to excellent yields. A series of control experiments were performed; the results suggest the involvement of radical pathways. Multiple radical intermediates were generated in situ and the overall process involved several different reactions, which proceeded self-sequentially in a single reactor. A labeling experiment using ${ }^{18} \mathrm{O}$-labeled $\mathrm{H}_{2} \mathrm{O}$ confirmed that the oxygen in the product was derived from TBHP, not from $\mathrm{H}_{2} \mathrm{O}$ in the TBHP solvent.
\end{abstract}

\section{Introduction}

In recent years, $\alpha$-acetoxyaryl ketones have attracted considerable interest because this structural motif is found in a variety of biologically active natural products and pharmaceuticals, and $\alpha$-acetoxyaryl ketones are widely used as synthetic intermediates [1-5]. Traditional methods for the preparation of $\alpha$-acyloxy ketones focus on the substitution reactions of $\alpha$-halo carbonyl compounds with alkaline carboxylates or carboxylic acids $[6,7]$, and transition-metal-catalyzed direct oxidative coupling reactions of carbonyl compounds with carboxylic acids (or their surrogates) [8,9]. Recently, robust approaches using organohypervalent iodine reagents and peroxide-mediated oxidative coupling have been developed [10,11]. Although impressive progress has been made [12], examples of the synthesis of $\alpha$-acetoxyaryl ketones through self-intermolecular oxidative 
coupling of aryl ketones are still rare. Yan and coworkers reported the preparation of $\alpha$-acyloxyaryl ketones from aryl ketones using a Pybox-copper(II) catalyst [13]. However, the substrate scope was limited to $\alpha$-substituted aryl ketones, and acetophenones were unsuitable for this conversion. In addition, this method requires harsh catalytic conditions, using scarce iron and copper complexes. The development of novel metalfree methods for the preparation of $\alpha$-acetoxyaryl ketones is therefore an attractive target for organic chemists. Simple, inexpensive, and metal-free methods [14,15], involving safe and clean oxidation procedures, need to be developed. Here, we report a metal-free, novel, and efficient self-intermolecular oxidative coupling procedure for the synthesis of $\alpha$-acetoxyaryl ketones from aryl ketones using $\mathrm{I}_{2}$ and tert-butyl hydroperoxide (TBHP) [16-18] (Scheme 1). Several oxidative cross-coupling methods have been developed for the synthesis of $\alpha$-acetoxy ketones from ketone derivatives and carboxylic acids [10], benzylic alcohols [19], toluene derivatives [20,21] and alkenes $[22,23]$ using TBHP as the oxidant (Scheme 1). However, to the best of our knowledge, this is the first example of the use of TBHP as the oxidant for the construction of $\alpha$-acetoxyaryl ketones from aryl ketones via self-intermolecular oxidative coupling.

\section{Results and Discussion}

In our first attempt, the reaction of acetophenone (1a) in the presence of an $\mathrm{I}_{2}$-TBHP system gave the desired product 2a in $46 \%$ yield. The yield increased to $71 \%$ when the reaction time was prolonged to $24 \mathrm{~h}$ (Table 1, entries 1-3). The reaction did not occur in the absence of $\mathrm{I}_{2}$ or $\mathrm{Na}_{2} \mathrm{CO}_{3}$, indicating that these species both play important roles in this reaction (Table 1 , entries 4 and 5). The reaction was almost unaffected by the solvent (Table 1, entries 3,6-8). Acetonitrile was slightly more effective than the other solvents tested. An increase in the amount of TBHP from 2.0 equiv to 4.0 equiv significantly affected the reaction efficiency, leading to a pronounced increase in the yield (Table 1, entry 9). Further increasing the TBHP loading did not have any beneficial effect (Table 1, entry 10). An increase in the amount of $\mathrm{I}_{2}$ from 0.1 equiv to 0.5 equiv did not affect product formation (Table 1, entry 11). However, decreasing the amount of $\mathrm{Na}_{2} \mathrm{CO}_{3}$ from 1.0 equiv to 0.1 equiv significantly decreased the product yield. The effects of other peroxides, i.e., di-tert-butyl peroxide (DTBP), benzoyl peroxide, dicumyl peroxide (DCP), cumene hydroperoxide (CHP), potassium hydrogen persulfate, and 3-chloroperoxybenzoic acid ( $m$-CPBA), on the reaction were investigated. All these peroxides gave sluggish reactions with poor yields, except

\section{Previous work:}

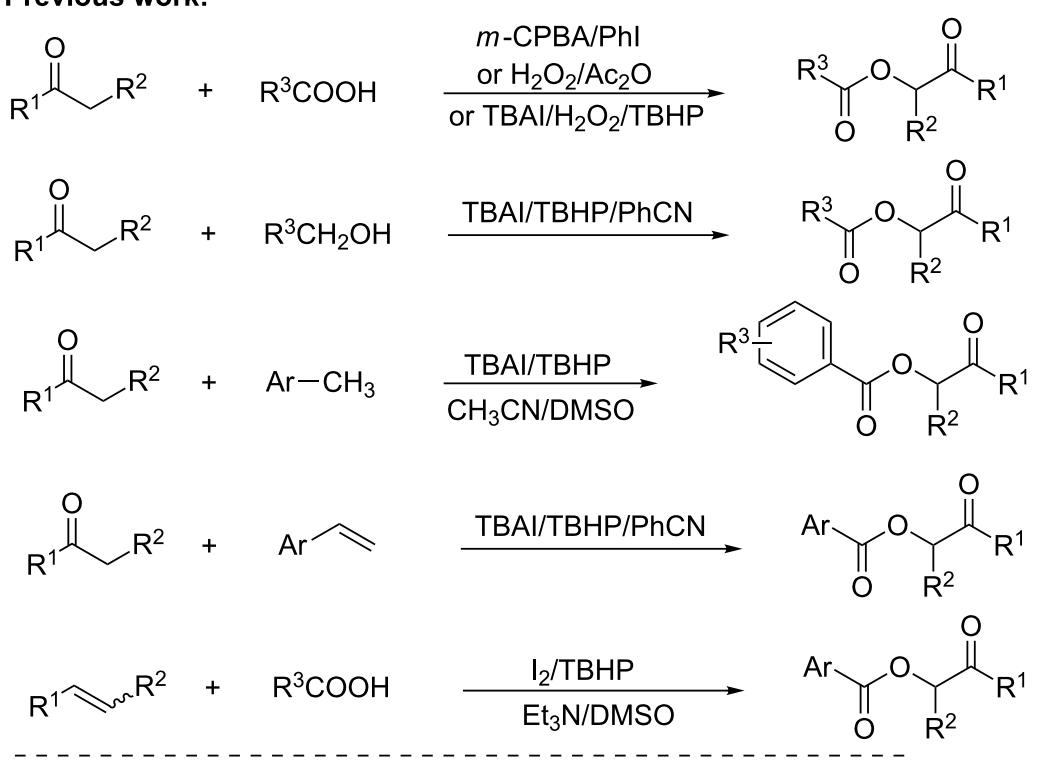

Present method:

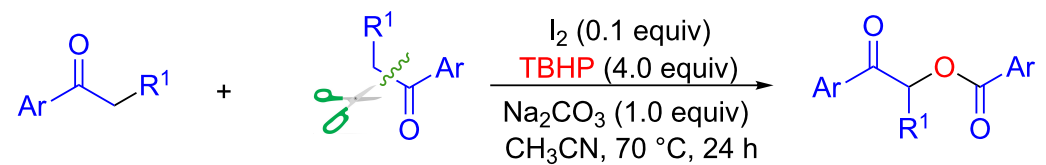


Table 1: Optimization studies ${ }^{\mathrm{a}}$.<smiles>CC(=O)c1ccccc1</smiles>

1a

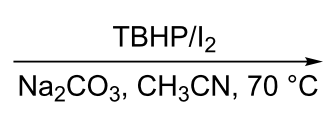

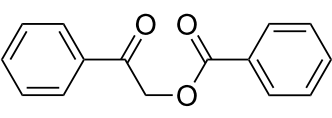

$2 a$

\begin{tabular}{|c|c|c|c|c|}
\hline Entry & peroxide (2.0 equiv) & solvent & Time $(h)$ & Yield\%b \\
\hline 1 & TBHP & $\mathrm{CH}_{3} \mathrm{CN}$ & 12 & 46 \\
\hline 2 & TBHP & $\mathrm{CH}_{3} \mathrm{CN}$ & 24 & 71 \\
\hline 3 & TBHP & $\mathrm{CH}_{3} \mathrm{CN}$ & 36 & 71 \\
\hline $4^{c}$ & TBHP & $\mathrm{CH}_{3} \mathrm{CN}$ & 24 & 0 \\
\hline $5^{d}$ & TBHP & $\mathrm{CH}_{3} \mathrm{CN}$ & 24 & 0 \\
\hline 6 & TBHP & dioxane & 24 & 70 \\
\hline 7 & TBHP & DCE & 24 & 68 \\
\hline 8 & TBHP & cyclohexane & 24 & 63 \\
\hline 9 & TBHP (4.0) & $\mathrm{CH}_{3} \mathrm{CN}$ & 24 & 84 \\
\hline 10 & TBHP (6.0) & $\mathrm{CH}_{3} \mathrm{CN}$ & 24 & 84 \\
\hline $11^{e}$ & TBHP (4.0) & $\mathrm{CH}_{3} \mathrm{CN}$ & 24 & 84 \\
\hline $12^{f}$ & TBHP (4.0) & $\mathrm{CH}_{3} \mathrm{CN}$ & 24 & 33 \\
\hline 13 & DTBP $(4.0)$ & $\mathrm{CH}_{3} \mathrm{CN}$ & 24 & 23 \\
\hline 14 & benzoyl peroxide (4.0) & $\mathrm{CH}_{3} \mathrm{CN}$ & 24 & 47 \\
\hline 15 & $\operatorname{DCP}(4.0)$ & $\mathrm{CH}_{3} \mathrm{CN}$ & 24 & 29 \\
\hline 16 & CHP (4.0) & $\mathrm{CH}_{3} \mathrm{CN}$ & 24 & 11 \\
\hline 17 & $\mathrm{~K}_{2} \mathrm{~S}_{2} \mathrm{O}_{8}(4.0)$ & $\mathrm{CH}_{3} \mathrm{CN}$ & 24 & 11 \\
\hline 18 & $m-\mathrm{CPBA}(4.0)$ & $\mathrm{CH}_{3} \mathrm{CN}$ & 24 & 81 \\
\hline $19^{9}$ & TBHP (4.0) & $\mathrm{CH}_{3} \mathrm{CN}$ & 24 & trace \\
\hline $20^{\mathrm{h}}$ & TBHP (4.0) & $\mathrm{CH}_{3} \mathrm{CN}$ & 24 & 84 \\
\hline
\end{tabular}

aReaction conditions: $1 \mathrm{a}(0.5 \mathrm{mmol}), \mathrm{I}_{2}$ ( 0.1 equiv), TBHP (2.0 equiv), $\mathrm{Na}_{2} \mathrm{CO}_{3}$ (1.0 equiv), solvent $(2.0 \mathrm{~mL}) ;{ }^{b} \mathrm{GC}$ yield; ${ }^{\mathrm{c}}$ without $\mathrm{I}_{2} ;{ }^{\mathrm{d}}$ without $\mathrm{Na}_{2} \mathrm{CO}_{3}$; $\mathrm{e}_{2}$ : 0.5 equiv; ${ }^{\mathrm{f}} \mathrm{Na}_{2} \mathrm{CO}_{3}: 0.1$ equiv; greaction temperature: rt; ${ }^{\mathrm{h}}$ reflux.

$m$-CPBA, which gave the desired product $\mathbf{2 a}$ in $81 \%$ yield (Table 1, entries 13-18). Finally, we investigated the effect of reaction temperature to this transformation, which indicated that the optimum reaction temperature is: $70{ }^{\circ} \mathrm{C}$ (Table 1, entries 19 and 20).

After the optimization study, the generality of the optimum conditions with various substituted aryl ketones was investigated (Scheme 2). Initially, acetophenone derivatives 1a-h were used; various electron-donating (i.e., methyl and methoxy) and electron-withdrawing (i.e., $\mathrm{F}^{-}, \mathrm{Br}^{-}$, and $\mathrm{Cl}^{-}$) substituents were well-tolerated under our reaction conditions. Acetophenones bearing electron-withdrawing substituents performed slightly better in this reaction than those bearing electron-donating substituents, and afforded the desired product in relatively high yields (2f, 2g, and $\mathbf{2 h}$ ).

The position of a given substituent on the phenyl ring of acetophenone affected the reaction slightly, and para-substituted acetophenones gave better results than ortho- and meta-substituted acetophenones (2b, 2c, and $\mathbf{2 d})$. The scope of this reaction was extended by varying the aliphatic part of the arone $(\mathbf{1} \mathbf{j}-\mathbf{n})$; for example, propiophenones and butyrophenones all reacted as anticipated to give the desired $\alpha$-acetoxyaryl ketones $\mathbf{2} \mathbf{j}-\mathbf{n}$ in moderate yields. In addition, different substituents on the phenyl ring had no discernible impact on the outcome. 1-(Thiophen-2-yl)ethanone (1i), which has a heteroaryl functionality, gave $\mathbf{2 i}$ in $83 \%$ isolated yield.

A series of control experiments were performed to clarify the reaction mechanism (Scheme 3). When the reactions were performed in the presence of an excess of the free-radical scavenger 2,2,6,6-tetramethylpiperidine- $N$-oxyl, product formation was completely suppressed (Scheme 3 , reaction 1 ), indicating that a radical pathway may be involved in this reaction. The oxygen source was identified by performing the reaction with excess ${ }^{18} \mathrm{O}$-labeled $\mathrm{H}_{2}{ }^{18} \mathrm{O}$; 2 a was obtained in $79 \%$ yield, with no ${ }^{18} \mathrm{O}$ in the product; this excludes the possibility of the 


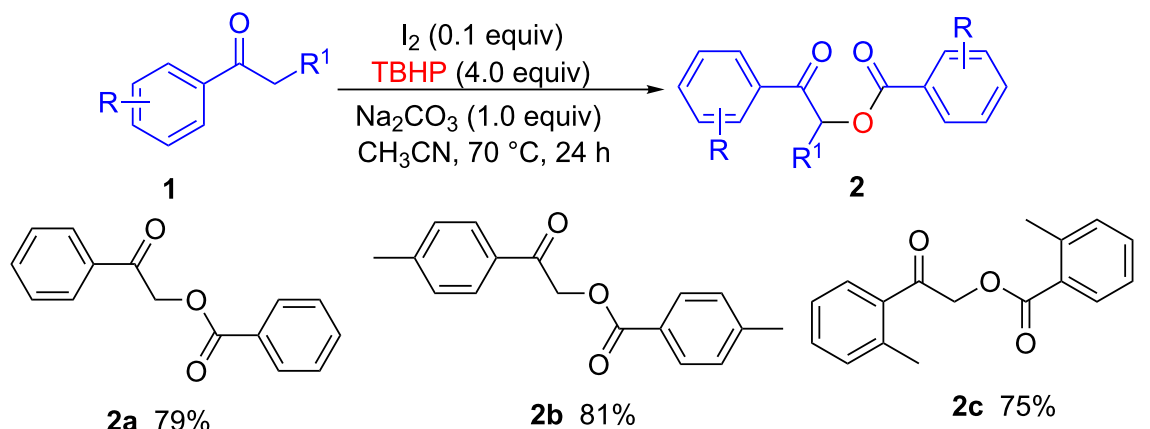<smiles>COc1cccc(C(=O)COC(=O)c2cccc(OC)c2)c1</smiles><smiles>O=C(COC(=O)c1ccccc1Cl)c1ccccc1Cl</smiles>

2g $78 \%$<smiles>O=C(COC(=O)c1ccccc1Br)c1ccccc1Br</smiles>

2h $86 \%$<smiles>O=C(COC(=O)c1cccs1)c1cccs1</smiles>

2i $83 \%$

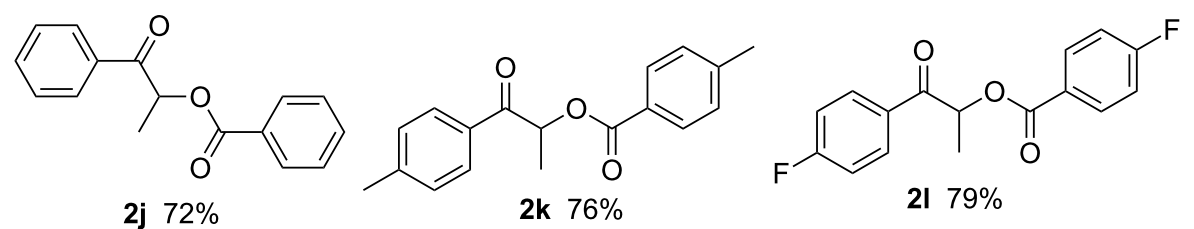

2j $72 \%$

2k $76 \%$<smiles>CCC(OC(=O)c1ccc(Cl)cc1)C(=O)c1ccc(Cl)cc1</smiles>

Scheme 2: Substrate scope. (All of these reactions were carried out on a 2.0 mmol scale using $\mathrm{CH}_{3} \mathrm{CN}(2.0 \mathrm{~mL})$ as a solvent.)

oxygen being derived from $\mathrm{H}_{2} \mathrm{O}$ in the TBHP solvent (Scheme 3, reaction 2). When 2-iodo-1-phenylethanone was used as a surrogate of 1a under the optimum conditions or in the absence of $\mathrm{I}_{2}, \mathbf{2 a}$ was isolated in $91 \%$ and $87 \%$ yields, respectively (Scheme 3, reactions 3 and 4). We also observed that $\mathbf{2 a}$ was obtained in almost quantitative yields when 1a was reacted with tert-butylperoxybenzoate (TBPB) or benzoic acid under the standard conditions (Scheme 3, reactions 5 and 6). These results suggest that 2-iodo-1-phenyl ketone, TBPB, and benzoic acid are generated in situ from $1 \mathbf{a}$ as intermediates.

The mechanism has not yet been clarified in detail. A probable catalytic cycle is proposed in Scheme 4 based on the above experimental results and previous literature reports. The process begins with the formation of $\alpha$-iodoaryl ketones 5 and $\mathbf{6}$ via iodination of aryl ketones with $\mathrm{I}_{2}$ and TBHP $[24,25]$. An I-/ $\mathrm{I}_{2}$ redox cycle promotes tert-butoxyl and tert-butylperoxyl radical formation from TBHP [26-28]. In the presence of TBHP and $I_{2}$, $\alpha$-iodoaryl ketones 5 and $\mathbf{6}$ are oxidized to a 1,2-diketone intermediate 7 and an $\alpha$-carbonyl radical $\mathbf{9}$, which can be further transformed to tert-butyl perester 8 and cation 11 [22]. The $\mathrm{I}^{-}$ anion can be reoxidized by tert-butyl perester 8 to regenerate $\mathrm{I}_{2}$, a tert-butoxyl radical, and an aromatic acid anion under alkaline conditions. Finally, the reactions between intermediates $\mathbf{8}$ and 9,10 and 11 or 5 all afford the final product, according to previous reports $[22,29]$.

\section{Conclusion}

In summary, we have developed an efficient, novel, and metalfree synthesis of $\alpha$-acetoxyaryl ketones from aryl ketones using 
<smiles>O=C(COC(=O)c1ccccc1)c1cccc(C(=O)OCC(=O)c2ccccc2)c1</smiles>

$1 \mathrm{a}$<smiles>[13CH3]CC(=O)c1ccccc1</smiles>

$1 a$<smiles>O=C(COC(=O)c1ccccc1)c1ccccc1</smiles>

2a $79 \%$<smiles>O=C(COC(=O)c1ccccc1)c1ccccc1</smiles>

2a $91 \%$

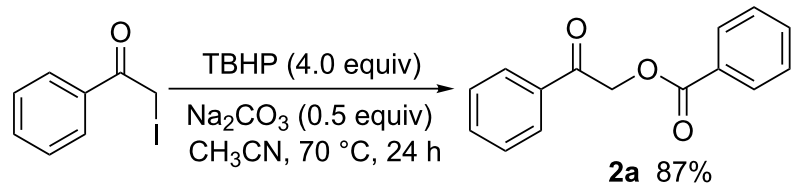
2a $87 \%$<smiles>CC(C)(C)OOC(=O)c1ccccc1</smiles><smiles>O=C(COC(=O)c1ccccc1)c1ccccc1</smiles>

$1 a$<smiles>[CH3+]C(=O)c1ccccc1</smiles>

1a<smiles>O=C(O)c1ccccc1</smiles>

Standard conditions<smiles>O=C(COC(=O)c1ccccc1)c1ccccc1</smiles>

2a $96 \%$

Scheme 3: Control reactions for clarifying the mechanism.

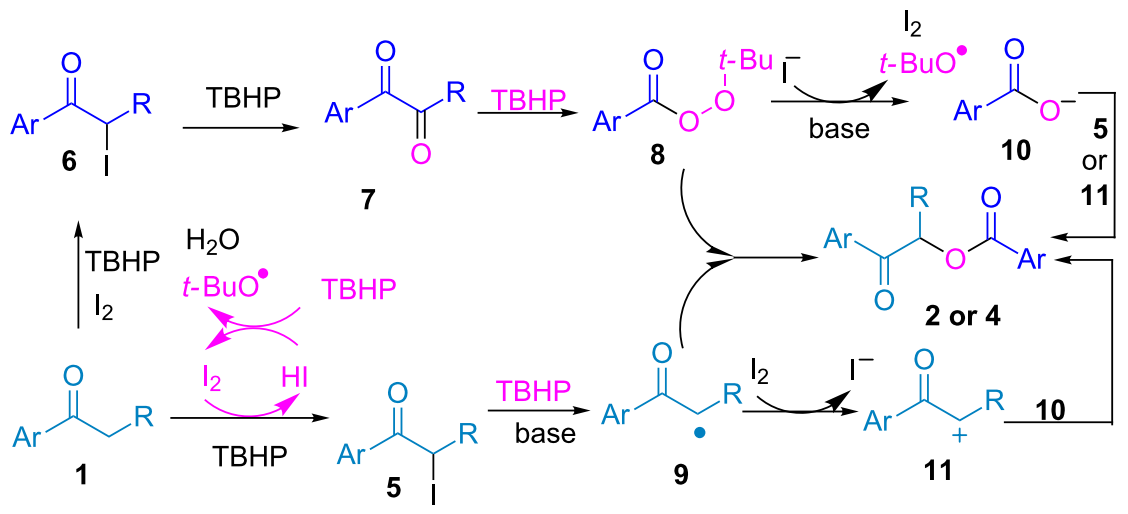

Scheme 4: Plausible mechanism.

$\mathrm{I}_{2}-$ TBHP. A facile $\alpha$-acylation reaction involving self-intermolecular oxidative coupling of aryl ketones was observed for the first time in the presence of $\mathrm{I}_{2}-\mathrm{TBHP}$. Multiple radical intermediates are generated in situ, and the overall process involves several different reactions, which proceed self-sequentially in a single reactor. The reaction conditions are mild and the substrate scope is broad. This method has good potential applications in organic synthesis and medicinal chemistry. The inside of the reaction mixture has not been studied in depth, but we have begun mechanistic studies. 


\section{Supporting Information}

\section{Supporting Information File 1}

Full experimental details and copies of NMR spectral data. [http://www.beilstein-journals.org/bjoc/content/ supplementary/1860-5397-13-107-S1.pdf]

\section{References}

1. Shindo, M.; Yoshimura, Y.; Hayashi, M.; Soejima, H.; Yoshikawa, T.; Matsumoto, K.; Shishido, K. Org. Lett. 2007, 9, 1963. doi:10.1021/ol0705200

2. Loner, C. M.; Luzzio, F. A.; Demuth, D. R. Tetrahedron Lett. 2012, 53, 5641. doi:10.1016/j.tetlet.2012.08.032

3. Murahashi, S., Susumu.; Saito, T.; Hanaoka, H.; Murakami, Y.; Naota, T.; Kumobayashi, H.; Akutagawa, S. J. Org. Chem. 1993, 58, 2929. doi:10.1021/jo00063a002

4. Green, T. W.; Wuts, P. G. M. Protective Groups in Organic Synthesis. Wiley: New York, 1991; p 87.

5. Akita, H.; Enoki, Y.; Yamada, H.; Oishi, T. Chem. Pharm. Bull. 1989, 37, 2876. doi:10.1248/cpb.37.2876

6. Levine, P. A.; Walti, A. Org. Synth. Coll. Vol. I/ 1943, 5.

7. Clark, J. H.; Miller, J. M. Tetrahedron Lett. 1977, 18, 599. doi:10.1016/S0040-4039(01)92703-0

8. Malova Krizkova, P.; Hammerschmidt, F. Eur. J. Org. Chem. 2013, 5143. doi:10.1002/ejoc.201300439

9. Cadierno, V.; Francos, J.; Gimeno, J. Organometallics 2011, 30, 852. doi:10.1021/om1010325

10. Uyanik, M.; Suzuki, D.; Yasui, T.; Ishihara, K. Angew. Chem. 2011, 123, 5443. doi:10.1002/ange.201101522

11. Ochiai, M.; Takeuchi, Y.; Katayama, T.; Sueda, T.; Miyamoto, K. J. Am. Chem. Soc. 2005, 127, 12244. doi:10.1021/ja0542800

12. Reddi,, R. N.; Gontala, A.; Prasad, P. K.; Sudalai, A. Asian J. Org. Chem. 2016, 5, 48. doi:10.1002/ajoc.201500355

13. Jia, W.-G.; Zhang, H.; Li, D.-D.; Yan, L.-Q. RSC Adv. 2016, 6, 27590. doi:10.1039/C6RA02186G

14. Nagano, T.; Jia, Z.; Li, X.; Yan, M.; Lu, G.; Chan, A. S. C.; Hayashi, T. Chem. Lett. 2010, 39, 929. doi:10.1246/cl.2010.929

15. Uyanik, M.; Suzuki, D.; Watanabe, M.; Tanaka, H.; Furukawa, K.; Ishihara, K. Chem. Lett. 2015, 44, 387. doi:10.1246/cl.141110

16. Roch, S. Science 2010, 327, 1376. doi:10.1126/science.1182300

17. Uyanik, M.; Suzuki, D.; Yasui, T.; Ishihara, K. Angew. Chem., Int. Ed. 2011, 50, 5331. doi:10.1002/anie.201101522

18. Uyanik, M.; Hayashi, H.; Ishihara, K. Science 2014, 345, 291. doi:10.1126/science.1254976

19. Guo, S.; Yu, J.-T.; Dai, Q.; Yang, H.; Cheng, J. Chem. Commun. 2014, 50, 6240. doi:10.1039/c4cc01652a

20. Reddi, R. N.; Prasad, P. K.; Sudalai, A. Org. Lett. 2014, 16, 5674. doi:10.1021/ol5027393

21. Chen, C.; Liu, W.; Zhou, P.; Liu, H. L. RSC Adv. 2017, 7, 20394. doi:10.1039/C7RA02298K

22. Mondal, B.; Sahoo, S. C.; Pan, S. C. Eur. J. Org. Chem. 2015, 3135. doi:10.1002/ejoc.201500233

23. Zhu, F.; Wang, Z.-X. Tetrahedron 2014, 70, 9819. doi:10.1016/j.tet.2014.11.002

24. Li, H.-Z.; Xue, W.-J.; Wu, A.-X. Tetrahedron 2014, 70, 4645. doi:10.1016/j.tet.2014.05.045
25. Mupparapu, N.; Vishwakarma, R. A.; Ahmed, Q. N. Tetrahedron 2015, 71, 3417. doi:10.1016/j.tet.2015.03.088

26. Lai, J.; Chang, L.; Yuan, G. Org. Lett. 2016, 18, 3194. doi:10.1021/acs.orglett.6b01412

27. Uyanik, M.; Ishihara, K. ChemCatChem 2012, 4, 177. doi:10.1002/cctc.201100352

28. Finkbeiner, P.; Nachtsheim, B. J. Synthesis 2013, 45, 979. doi:10.1055/s-0032-1318330

29. Zhu, M.; Wei, W.; Yang, D.; Cui, H.; Cui, H.; Sun, X.; Wang, H. Org. Biomol. Chem. 2016, 14, 10998. doi:10.1039/C6OB02173E

\section{License and Terms}

This is an Open Access article under the terms of the Creative Commons Attribution License

(http://creativecommons.org/licenses/by/4.0), which permits unrestricted use, distribution, and reproduction in any medium, provided the original work is properly cited.

The license is subject to the Beilstein Journal of Organic Chemistry terms and conditions: (http://www.beilstein-journals.org/bjoc)

The definitive version of this article is the electronic one which can be found at: doi:10.3762/bjoc. 13.107 